\title{
Adsorption of creatinine on active carbons with nitric acid
}

\section{hydrothermal modification}

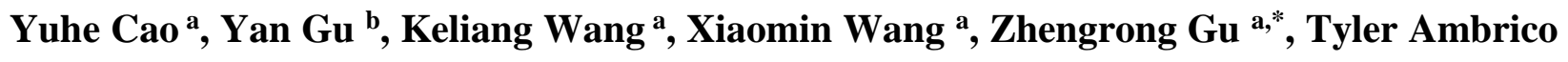 \\ c, Maria Andrea Castro ${ }^{\text {d, }}$ Joun Lee ${ }^{\text {e, William Gibbons }}{ }^{\text {, }}$, James A. Rice ${ }^{\text {g }}$ \\ ${ }^{a}$ Agricultural and Biosystems Engineering Department, South Dakota State University, Brookings, \\ SD, USA \\ ${ }^{b}$ Institute of Chemical Industry of forest Product, NanJing, Jiangsu, China \\ ${ }^{\mathrm{c}}$ Department of Physics and Astronomy, Stony Brook University, Stony Brook, NY, USA \\ ${ }^{\mathrm{d}}$ Department of Chemistry, University of Iowa, Iowa City, IA, USA \\ ${ }^{\text {e }}$ Central Microscopy Research Facility, University of Iowa, Iowa City, IA, USA \\ ${ }^{\mathrm{f}}$ Department of Biology and Microbiology, South Dakota State University, Brookings, SD, USA \\ ${ }^{\mathrm{g}}$ Department of Chemistry and Biochemistry, South Dakota State University, Brookings, SD, USA
}

\section{*Correspondence:}

Zhengrong Gu

North Campus Drive 1400, Agricultural and Biosystems Engineering, South Dakota State University, Brookings, SD 57007, USA 
Tel: +1-605-688-5372 Fax:+1-605-688-6764 Email: Zhengrong.gu@sdstate.edu

\section{Abstract}

The adsorption of creatinine on active carbons was studied. Original active carbon (AC) and AC samples modified by nitric acid hydrothermal modification were assessed for their ability to adsorb creatinine. The pore structure and surface properties of the AC samples were characterized by $\mathrm{N}_{2}$ adsorption, temperature programmed desorption (TPD), Fourier Transform Infrared spectroscopy (FTIR), and X-ray photoelectron spectrometer (XPS). It indicated that 4M $\mathrm{HNO}_{3}$ hydrothermal modification with $180{ }^{\circ} \mathrm{C}$ was an efficient method in improvement of the creatinine adsorption. The improved adsorption capacity can be attributed mainly to an increase in the acidic oxygen-containing functional groups. The adsorption of creatinine over AC may involve an interaction with the acidic oxygen-containing groups on AC. Langmuir and Freundlich adsorption models were applied to describe the experimental isotherm and isotherm constants. Equilibrium data fitted very well to the Freundlich model in the entire saturation range (3.58-59.08

$\mathrm{mg} \mathrm{L}^{-1}$ ). The maximum adsorption capacities of $\mathrm{AC}$ modified with $180{ }^{\circ} \mathrm{C}$ is $62.5 \mathrm{mg} \mathrm{g}^{-1}$ according to the Langmuir model. Pseudo first-order and second-order kinetic models were used to describe the kinetic data and the rate constants were evaluated. The experimental data fitted well to the second-order kinetic model, which indicates that the chemical adsorption was the rate-limiting step, instead of mass transfer.

Keyword: Creatinine; Active carbon; Nitric acid; Hydrothermal; Adsorption 


\subsection{Introduction}

Creatinine (2-amino-1-methyl-5H-imidazol-4-one, $\mathrm{C}_{4} \mathrm{H}_{7} \mathrm{~N}_{3} \mathrm{O}$ ) is a typical uremic toxin in the human metabolism products. The accumulation of creatinine in the blood causes a series of toxic symptoms such as diabetic nephropathy, eclampsia, glomerulonephritis, muscular dystrophy, and preeclampsia, meanwhile which also reduces the kidney function and accelerates the renal decline [1].

Creatinine is commonly removed by haemodialysis. However, creatinine cannot be effectively removed by a single haemodialysis process. Haemoperfusion, the direct contact of the patients' blood with sorbents, can efficiently remove toxins without introducing any other substances into the blood [2]. Porous materials such as active carbon and polymeric resin are mainly used in haemoperfusion [3] to adsorb the creatinine. To date, porous materials like active carbon [4], zeolites [5-7], carbon nanotubes [8], molecularly imprinted polymers [9-11], and metal-organic frameworks [12] for artificial kidney application of creatinine adsorption have been investigated.

Among those adsorbents, activated carbon (AC) has a long record as a cheap sorbent in blood purification in the case of intoxications, acute and chronic renal failure as well as liver failure [13-15]. Moreover, carbon materials have chemically inert surface and excellent biocompatibility, they are more powerful sorbents than their inorganic or organic counterparts because they do not require special coatings [16].

On the other hand, creatinine not only exists in serum, but also in the alimentary canal (stomach and intestine) [17]. Active carbon can be used as oral sorbents to reduce the creatinine concentration in serum. Creatinine and other waste nitrogenous waste products (urea, etc) which diffuse into the gastrointestinal tract from the blood are bound to active carbon and excreted in the 
feces, creating a concentration gradient for continued diffusion, giving place to a process this intestinal dialysis. Therefore, active carbon can adsorb the creatinine, uric acid and other toxins in gastrointestinal tract quickly, lightening the burden of kidney excreting toxins [18, 19].

Both porous structure and surface chemistry of ACs may play an important role in determining their adsorption performance. Since the performance of AC in most applications is influenced by its surface chemistry, the modification of its properties has been the target of a variety of treatments. Nitric acid has been used to introduce carbon-oxygen surface groups in AC to increase the adsorption capacity for phenol [20] and sulfur compounds [21] in aqueous phase. Nitric acid modified AC samples were also used for vapor adsorption [22], which decreased the butanol adsorption capacity due to the increased oxygen-containing functional groups on the adsorbents' surface [23]. It indicates that different adsorbates may have different interaction with the oxidized AC samples. To improve the adsorption performance of AC for removing creatinine, hydrothermal modification of the commercial AC was conducted in the present study by using 4 $\mathrm{M} \mathrm{HNO}_{3}$ at $120^{\circ} \mathrm{C}, 150{ }^{\circ} \mathrm{C}$ and $180^{\circ} \mathrm{C}$, respectively. To our knowledge, similar research has not been reported so far.

\subsection{Materials and methods}

\subsection{Materials}

$\mathrm{HNO}_{3}$ and creatinine (Assay Percent Range: $99+\%, \mathrm{C}_{4} \mathrm{H}_{7} \mathrm{~N}_{3} \mathrm{O}$ ) were purchased from Thermo Fisher Scientific Inc. All of these chemicals were analytical grade. Commercial AC was purchased from Thermo Fisher Scientific Inc. Different kinds of modified AC were obtained by reaction between commercial $\mathrm{AC}$ and $4 \mathrm{M} \mathrm{HNO}_{3}$ at different temperatures.

\subsection{Methods}




\subsubsection{Modification of AC}

The commercial AC was washed by boiling water with a Soxhlet extractor for 2 hours. The wet $\mathrm{AC}$ was dried at $105{ }^{\circ} \mathrm{C}$ for 24 hours. $3 \mathrm{~g}$ of the dried $\mathrm{AC}$ was reacted with $40 \mathrm{ml} 4 \mathrm{M} \mathrm{HNO}_{3}$ in a sealed PTFE reactor $(50 \mathrm{ml})$ at 120,150 , and $180{ }^{\circ} \mathrm{C}$ for 1 hour respectively. These samples are denoted as 120-AC, 150-AC, and 180-AC. After reaction, the reactant was cooled and filtered, and washed with deionized water under vacuum filtration until the $\mathrm{pH}$ value of the permeate was 7. Finally, the washed AC was dried in a vacuum oven at $105^{\circ} \mathrm{C}$ overnight.

\subsubsection{Chemical and textural characterization for absorbents}

The characterization of the porous texture of the ACs was carried out by the analysis of the adsorption isotherm adsorption of $\mathrm{N}_{2}$ using an ASAP 2020 Micropore Analyzer. The total pore volume was determined at relative pressure $0.995 \mathrm{P}_{0}$, and the specific surface area was calculated from the BET method. The micropore and mesopore volume and the pore size distribution were determined by the density functional theory (DFT) for samples based on the $\mathrm{N}_{2}$ isotherm adsorption data.

Temperature-programmed desorption (TPD) was performed using a Micrometrics Autochem II Chemisorption Analyzer to investigate the oxygen content of these four AC samples. The carbon sample $(0.05 \mathrm{~g})$ was placed in a U-shaped quartz tube inside an electrical furnace and heated at $10^{\circ} \mathrm{C} / \mathrm{min}$ up to $1000^{\circ} \mathrm{C}$ using a constant flow rate of helium (the flow rate of the vapor, carrier, and reference were set at 0,60 , and $60 \mathrm{~cm}^{3} / \mathrm{min}$ respectively). The thermal conductivity detector (TCD) signals were monitored during the thermal analysis, and the corresponding TCD spectra was obtained. 
In order to analyze the functional groups on the surface, FTIR analysis of AC samples were carried out by using UV-3600 spectrophotometer within the range of $600-4000 \mathrm{~cm}^{-1}$. The AC samples were dried in an oven at $110{ }^{\circ} \mathrm{C}$ for overnight before the FTIR analysis. XPS analysis was carried out using Kratos Axis Ultra X-ray photoelectron spectrometer with concentric hemispherical electron energy analyzers combined with the established delay-line detector (DLD). The incident radiation monochromatic $\mathrm{Al} \mathrm{K \alpha} \mathrm{X}$-ray $(1486.6 \mathrm{eV})$ at $150 \mathrm{~W}$ (accelerating voltage $15 \mathrm{kV}$, emission current $10 \mathrm{~mA}$ ) was projected $45^{\circ}$ to the sample surface and the photoelectron data was collected at takeoff angle of $\theta=90^{\circ}$. The absolute energy scale was calibrated to $\mathrm{Cu} 2 \mathrm{p}_{3 / 2}$ peak binding energy at $932.6 \mathrm{eV}$ using sputter etched $99.9999 \%$ pure copper foil. The base pressure in the analysis chamber was maintained at $1.0 \times 10^{-9}$ torr. Low energy electrons were used for charge compensation to neutralize the sample. Carbon powders were pressed onto $99.999 \%$ pure Indium foil for analysis. Survey scans were taken at pass energy of $160 \mathrm{eV}$, and carried out over $1200 \mathrm{eV}$ $\sim-5 \mathrm{eV}$ binding energy range with $1.0 \mathrm{eV}$ steps and a dwell time of $200 \mathrm{~ms}$. High resolution scans of $\mathrm{C} 1 \mathrm{~s}, \mathrm{O} 1 \mathrm{~s}$, and $\mathrm{N} 1 \mathrm{~s}$ were taken at pass energy of $20 \mathrm{eV}$ with $0.1 \mathrm{eV}$ steps and a dwell time of $1000 \mathrm{~ms}$. The spectra analyses were carried out using CasaXPS version 2.3.17dev6.4k. Shirley type background was routinely used to account for inelastically scattered electrons that contribute to the broad background. Transmission corrected RFS/Kratos library relative sensitivity factors (RSFs) was used for elemental quantification. The spectra were calibrated using adventitious carbon C 1s peak at $285.0 \mathrm{eV}$.

\subsubsection{Quantification of creatinine}

To determine the amount of creatinine adsorbed by the adsorbents, a standard curve was used to calculate the creatinine amount in the solution. Creatinine was dissolved in distilled water, and creatinine solutions with different concentrations $(2,4,8,10,20,40,60,80,100,120,140$, 
and $160 \mathrm{mg} / \mathrm{L}$ ) were prepared. The ultraviolet (UV) region of $120 \mathrm{mg} / \mathrm{L}$ creatinine solution is scanned from 200 to $400 \mathrm{~nm}$ by a Shimadzu UV 2450 spectrophotometer (Tokyo, Japan). As is shown in Fig. S1, the wavelength of maximum absorbance is $230 \mathrm{~nm}$. Therefore, the absorbance of the solution was measured at $230 \mathrm{~nm}$. The standard curve was plotted according to the concentration and absorbance, which is shown in Fig. S2. Regression of the standard absorbance with concentration typically resulted in an $\mathrm{R}^{2} \geqslant 0.99$.

\subsubsection{Batch equilibrium}

The creatinine was dissolved in deionized water to the required concentration. In experiments of equilibrium adsorption isotherm, AC sample (50 mg) of and creatinine solution (20 $\mathrm{mL}$ ) were place in a $100 \mathrm{~mL}$ Erlenmeyer flask and shaken for $2 \mathrm{~h}$ by an incubator at the constant temperature of $37^{\circ} \mathrm{C}$. Each used a range of initial creatinine concentration was 40, 60, 80, 100, 120, 140 and $160 \mathrm{mg} / \mathrm{L}$ at $\mathrm{pH}$ 7. The AC sample was removed via a Millipore membrane filter $(0.20 \mu \mathrm{m})$ and the permeate was measured in the UV Spectrometer at $230 \mathrm{~nm}$ to determine the concentration of creatinine in the solution. Every value reported contained at least three separate measurements, and standard deviation was less than 5\%. The amount of adsorption at equilibrium $\mathrm{q}_{\mathrm{e}}(\mathrm{mg} / \mathrm{g})$ was calculated as follows:

$$
q_{e}=\frac{\left(C_{0}-C_{e}\right) \times V}{W}
$$

Where $\mathrm{C}_{0}$ and $\mathrm{C}_{\mathrm{e}}(\mathrm{mg} / \mathrm{L})$ are the initial and equilibrium creatinine concentration respectively. V (L) is the volume of the solution and $\mathrm{W}(\mathrm{g})$ is the weight of AC used.

\subsubsection{Batch kinetic}


In experiments of batch kinetic adsorption, 50mg of different AC samples were weighed and both the samples and the $160 \mathrm{mg} / \mathrm{L}$ creatinine solution were heated to $37^{\circ} \mathrm{C}$ in an incubator. The $160 \mathrm{mg} / \mathrm{L}$ creatinine solution was mixed in the incubator constantly at $100 \mathrm{rpm}$. Once the samples warmed, 20mL of creatinine solution were added to each sample in Erlenmeyer flasks and samples were removed at $1,3,5,15,30,60$ or $120 \mathrm{~min}$ via membrane filters. The creatinine concentration was determined as above-mentioned measuring method.

\subsubsection{Data analysis}

The widely used Langmuir isotherm has found successful application in many real adsorption processes and is expressed as:

$q_{e}=\frac{Q b C_{e}}{1+b C_{e}}$

which can be rearranged to obtain a linear form

$$
\frac{C_{e}}{q_{e}}=\frac{1}{Q b}+\frac{C_{e}}{Q}
$$

where $\mathrm{Q}\left(\mathrm{mg} \mathrm{g}^{-1}\right)$ refers to the monolayer adsorption capacity, $\mathrm{q}_{\mathrm{e}}$ is amount of adsorption at equilibrium, $\mathrm{C}_{\mathrm{e}}\left(\mathrm{mg} \mathrm{L}^{-1}\right)$ is the creatinine concentration at equilibrium and $\mathrm{b}$ is the Langmuir constant.

The Freundlich isotherm, used for isothermal adsorption, is a special case for heterogeneous surface energy in which the energy term in the Langmuir equation varies as a function of surface coverage strictly due to variation of the adsorption [24]. The Freundlich equation is given as:

$$
\ln q_{e}=\ln k_{f}+\frac{1}{n} \ln C_{e}
$$


where $\mathrm{C}_{\mathrm{e}}$ is the equilibrium concentration of adsorbate $\left(\mathrm{mg} \mathrm{L}^{-1}\right), \mathrm{q}_{\mathrm{e}}$ is the amount of the creatinine adsorbed by the adsorbents at equilibrium $\left(\mathrm{mg} \mathrm{g}^{-1}\right), \mathrm{k}_{\mathrm{f}}\left((\mathrm{mg} / \mathrm{g})\left(\mathrm{dm}^{3} / \mathrm{mg}\right)^{1 / \mathrm{n}}\right)$ and $\mathrm{n}$ are indicators of adsorption capacity and adsorption intensity, respectively. $\mathrm{k}_{\mathrm{f}}$ and $\mathrm{n}$ can be determined from the linear plot of $\ln \mathrm{q}_{\mathrm{e}}$ versus $\ln \mathrm{C}_{\mathrm{e}}$.

In order to investigate the mechanism of adsorption, the pseudo first-order and secondorder equations were used to test the experimental data. The first-order rate expression of Lagergren [13] is given as:

$$
\log \left(q_{e}-q\right)=\log q_{e}-\frac{k_{1} t}{2.303}
$$

where $\mathrm{q}_{\mathrm{e}}$ and $\mathrm{q}$ are the amounts of urea nitrogen adsorbed onto adsorbent at equilibrium and at time $\mathrm{t}$, respectively, and $\mathrm{k}_{1}\left(\mathrm{~min}^{-1}\right)$ is the rate constant of first-order adsorption. The secondorder kinetic model is expressed as:

$$
\frac{t}{q}=\frac{1}{k_{2} q_{e}^{2}}+\frac{t}{q_{e}}
$$

Where $\mathrm{k}_{2}\left(\mathrm{~g} \mathrm{mg}^{-1} \mathrm{~min}^{-1}\right)$ is the rate constant of second-order adsorption.

\subsection{Results and discussion}

\subsection{Physicochemical properties of active carbons}

\subsubsection{Pore structure characterization}

Nitrogen adsorption-desorption isotherms of unmodified AC, 120-AC, 150-AC and 180$\mathrm{AC}$ are shown in Fig. 1A. All nitrogen adsorption isotherms are of type II according to the classification by Brunauer et al [25]. The $\mathrm{N}_{2}$ adsorption capacity on the ACs increased in the order of $120-\mathrm{AC}<150-\mathrm{AC}<180-\mathrm{AC}<\mathrm{AC}$. A hysteresis loop was observed at the relative high pressure 
for each AC sample, indicating the presence of mesopores, which can also be found from the density functional theory (DFT) mesopores size distribution of the ACs, as is shown in Fig. 1B. It indicates that the pore volumes for micropores (smaller than $2 \mathrm{~nm}$ ) and mesopores (from $2 \mathrm{~nm}$ to $50 \mathrm{~nm}$ ) were slightly decreased for 120-AC and 150-AC samples. Fig. 1C shows the cumulative pore volumes for the AC samples, the curves for 120-AC and 150-AC, 180-AC and AC are almost overlapped respectively, which indicates their pore size distributions are almost the same for each pair. However, compared with the untreated AC, the total pore volume decreased from 0.76 to $0.70,0.70$, and $0.72 \mathrm{~cm}^{3} \mathrm{~g}^{-1}$ for $120-\mathrm{AC}, 150-\mathrm{AC}$ and $180-\mathrm{AC}$ respectively, which is shown in Table 1. The pores less than $50 \mathrm{~nm}$ (micropore volume plus mesopore volume) was decreased from 0.45 to $0.41 \mathrm{~cm}^{3} \mathrm{~g}^{-1}$ for both $120-\mathrm{AC}$ and $150-\mathrm{AC}$, while there is no change for AC treated with $180{ }^{\circ} \mathrm{C}$. With the total pore volume decreased after the modification, the BET surface areas for the AC-120, AC-150, and AC-180 decreased from 909 (unmodified AC) to 847, 869, $883 \mathrm{~m}^{2} \mathrm{~g}^{-1}$, respectively (Table 1).

The nitric acid hydrothermal treatment decreased the micopores volume for $0.03,0.02$ and $0.01 \mathrm{~m}^{2} \mathrm{~g}^{-1}$ at 120,150 , and $180{ }^{\circ} \mathrm{C}$, respectively, which can be attributed to partial destruction of the porous structure of the original sample due to the erosion of micropore walls $[20,26]$. The mesopore volume decreased from 0.16 to $0.15 \mathrm{~cm}^{3} \mathrm{~g}^{-1}$ with reaction temperature increased from 120 to $150{ }^{\circ} \mathrm{C}$, which caused mesopores partially transferred into micropores [23]. It is likely due to the partial destruction of the pore structure and the introduced oxygen-containing functional groups at the active sites at the entrance of the mesopores $[20,26]$. This resulted in the average pore diameter of the 120-AC and 150-AC decreased from 3.34 (unmodified AC) into 3.31 and $3.22 \mathrm{~nm}$, respectively (Table 1). 
On the contrary, compared with $150-\mathrm{AC}$ the mesopore volume slightly increased $\left(0.01 \mathrm{~cm}^{3}\right.$ $\mathrm{g}^{-1}$ ) for 180-AC. Higher temperature enhanced oxidation reaction much more greatly, causing more robust oxidation and etching of the carbon matrix of AC. It generated some new micropores, meanwhile, some of the micropores were widened into mesopores. Therefore, the average pore diameter of 180 -AC (3.26 nm) was slightly larger than that of 150-AC (3.22 nm), as is shown in Table 1.

\subsubsection{Oxygen-containing functional groups on ACs}

Temperature-programmed desorption (TPD) was employed to investigate the functional groups generated by $\mathrm{HNO}_{3}$ modification [22]. The carrier gas helium and the detected gases $(\mathrm{CO}$, $\mathrm{O}_{2}$ and $\mathrm{CO}_{2}$ ) have different thermal conductivities. TCD signals from the evolved gases were recorded and the areas under the peak were proportional to the amount of gases produced. Therefore, the TPD profile roughly indicates the amount of oxygen-containing functional groups.

Fig. 1D displays the TPD spectra arising from oxygenated groups released as $\mathrm{CO}$ and $\mathrm{CO}_{2}$ from the surface of ACs. The TPD profile measured for the untreated AC was also included. The quantity of oxygenated groups released during treatment was directly related to the temperature used to treat AC. Generally, carboxylic functional groups decompose and release $\mathrm{H}_{2} \mathrm{O}$ at lower temperatures $\left(100{ }^{\circ} \mathrm{C}\right.$ to $\left.400{ }^{\circ} \mathrm{C}\right)$, while anhydride and lactone groups decompose at higher temperatures $\left(427^{\circ} \mathrm{C}\right)$ [27-29]. In this study, the peaks formed between $400-1000{ }^{\circ} \mathrm{C}$ were assumed to be $\mathrm{CO}_{2}$ and $\mathrm{CO}[30]$, and the $\mathrm{CO}$ was possibly derived from the decomposition of phenols, ethers and carbonyls/quinones [31-33]. The order of oxygen-containing functional group's amount was $\mathrm{AC}-180>\mathrm{AC}-150>\mathrm{AC}-120>$ unmodified $\mathrm{AC}$ according to the TPD profiles. The level of oxygen functional groups that are created on the AC surface is dependent on the treatment conditions, including nitric acid concentration, temperature and amount of carbon loaded [34]. It 
indicates that higher temperature can generate more oxygen-containing functional groups due to more vigorous oxidation with higher temperature.

As is shown in Fig. S3, there are two major characteristic peaks in the range of 1800-1400 $\mathrm{cm}^{-1}$, which are mainly absorption bands of $\mathrm{C}=\mathrm{O}$ and aromatic ring. The peak centered at $1722 \mathrm{~cm}^{-}$ ${ }^{1}$ can be contribution from the stretching vibrations of carboxyl groups $(\mathrm{C}=\mathrm{O})$ on the edges of layer planes or from conjugated groups in the lactone groups. The peak at $1563 \mathrm{~cm}^{-1}$ can be assigned to asymmetric $\mathrm{COO}^{-}$vibration. The peak around $1158 \mathrm{~cm}^{-1}$ can be ascribed to the both $\mathrm{C}-\mathrm{O}$ stretching and $\mathrm{O}-\mathrm{H}$ bending modes in phenolic and carboxylic groups. Compared with the unmodified AC, it was observed that the 180 -AC had higher absorption intensity at 1722,1563 and $1158 \mathrm{~cm}^{-1}$, indicating an increase in carboxyl, lactone, and hydroxyl groups [21]. After TPD, these absorptions decreased significantly. It means that high temperature decomposed those oxygen-containing functional groups.

It was found that the $\mathrm{HNO}_{3}$ hydrothermal oxidation would change the total surface area and pore distribution to some extent as discussed above, but the surface morphology of ACs were almost the same, as is shown in Fig. S4. However, after $\mathrm{HNO}_{3}$ treatment, oxygen content in the AC increased significantly, which has been verified by SEM-EDS (Table S1). The order of total oxygen content was unmodified AC $(4.39$, wt. \%) $<120$-AC (7.67, wt. \%) $<150-\mathrm{AC}(8.50$, wt. \%) $<180-\mathrm{AC}(11.83$, wt. \%).

The kinds and amounts of surface functional groups on unmodified AC and 180-AC were more quantitatively determined by the XPS method. Fig. 2 Shows the C 1s and O 1s XPS spectra of unmodified AC and 180-AC. After baseline correction using Shirley's method, the C 1s peak of these two samples can be deconvoluted into five peaks centered at 284.6, 286.0, 287.3, 288.9, and $290.3 \mathrm{eV}$, which are ascribed to the graphitic $\mathrm{C}=\mathrm{C}$ bond, $-\mathrm{C}-\mathrm{O},-\mathrm{C}=\mathrm{O}, \mathrm{O}-\mathrm{C}=\mathrm{O}$, and $\mathrm{CO}_{3}$ groups, 
respectively [35-37]. The $\mathrm{O}$ 1s peak of each sample contains contributions from two Gaussian deconvoluted peaks centered at 532.0 and $534.0 \mathrm{eV}$, which are attributed to $=\mathrm{O}$ and $-\mathrm{O}-$ species, respectively [38]. Table 2 shows the molar ratio distribution of surface functional groups on unmodified AC and 180-AC from a comparison of each deconvoluted peak. By contrast, oxidation at $180{ }^{\circ} \mathrm{C}$ increased $\mathrm{C}$-O group amount (199.8\% higher than the unmodified AC) accompanied by simultaneous increase in $\mathrm{C}=\mathrm{O}, \mathrm{O}-\mathrm{C}=\mathrm{O}($ e.g., $-\mathrm{COOH}$ ). The $\mathrm{C} 1$ s spectra (Table 2) displayed higher carbonyl (or quinone) and carboxylic (or ester or lactone) groups contents in $180-\mathrm{AC}(2.81 \%$ of $\mathrm{C}=\mathrm{O}$ group; $2.81 \%$ of $\mathrm{O}-\mathrm{C}=\mathrm{O}$ groups $)$ compared to the unmodified $\mathrm{AC}$ sample $(1.96 \%$ of $\mathrm{C}=\mathrm{O}$, and $2.25 \%$ of $\mathrm{O}-\mathrm{C}=\mathrm{O}$ ). However, the nitric acid modification slightly reduced the concentration of $\mathrm{CO}_{3}$ from $3.10 \%$ to $2.90 \%$, probably due to the removal of carbonate existing in unmodified AC during the oxidation treatment. The O1s spectra shows the intensity of the oxygen components in form of $-\mathrm{O}$ and $=\mathrm{O}$. As is shown in Fig. 2, the intensity of the 180-AC was higher than that of unmodified AC. The oxygen content of $180-\mathrm{AC}$ was $4.17 \%$ for $=\mathrm{O}$ and $5.67 \%$ for $-\mathrm{O}-$, which was significantly higher than unmodified $\mathrm{AC}(1.88 \%$ for $=\mathrm{O}$ and $2.15 \%$ for $-\mathrm{O}-)$.

\subsection{Equilibrium adsorption}

Fig. 3A shows the equilibrium adsorption of creatinine onto the four AC samples with different concentrations. With the increasing initial concentration of creatinine, the equilibrium adsorption capacity for creatinine increased gradually until the equilibrium condition is reached [39], showing the favourable adsorption of creatinine on AC samples at higher concentrations. It indicates that the AC-180 has the highest adsorption capacity among these four adsorbents. To compare the saturation adsorption capacity, we also investigated the saturation adsorption for ACs. As is shown in Fig. 3B, the creatinine adsorbed by the ACs was increasing until the creatinine solution volume increased to $80 \mathrm{ml}$. The 180-AC got the highest amount of creatinine adsorption 
at equilibrium $\left(64.5 \mathrm{mg} \mathrm{g}^{-1}\right)$, which is 0.29 times more than the unmodified AC $\left(50.0 \mathrm{mg} \mathrm{g}^{-1}\right)$.It indicates the modification greatly enhanced the creatinine adsorption capacity.

\subsubsection{Langmuir isotherm}

A linearized plot of $\mathrm{C}_{\mathrm{e}} / \mathrm{q}_{\mathrm{e}}$ versus $\mathrm{q}_{\mathrm{e}}$ was obtained from the model shown in Fig. S5. Q and b is computed from the slops and intercepts of different straight lines representing different AC samples. Table 3 lists the calculated results. It indicates that the computed maximum monolayer capacity Q of creatinine onto unmodified AC, 120-AC, 150-AC and 180-AC are 55.6, 71.4, 62.5 and $62.5 \mathrm{mg} \mathrm{g}^{-1}$, respectively. However, the fits are not quite well for the AC samples under the creatinine concentration ranges studied, and correlation coefficients of unmodified AC, 120-AC, 150-AC and 180-AC are $0.9422,0.9070,0.9335$ and 0.9830 , respectively. It indicates that the adsorption of creatinine was not typical monolayer [40].

\subsubsection{Freundlich isotherm}

The values of the Freundlich adsorption isotherm constant $\mathrm{n}$ were 2.02, 1.63, 1.95 and 2.12 for the unmodified AC, 120-AC, 150-AC and 180-AC, respectively (Table 3). All the values were within $1-10$, indicating that the adsorption for creatinine by these adsorbents were favorable [41, 42]. As a result, the Freundich adsorption model, which was considered to be the uneven adsorption mainly via monolayer chemical adsorption and a small amount of physical adsorption on the surface of the adsorbent, could be applied in the adsorption process for creatinine.

\subsection{Kinetics of adsorption}

Fig. 3D, $\mathrm{F}$ and $\mathrm{H}$ show the adsorption kinetics of creatinine onto AC samples at initial concentrations 160,120 and $80 \mathrm{mg} \mathrm{L}^{-1}$ at $37^{\circ} \mathrm{C}$. It shows that adsorption was quick in the first 15 min and the equilibrium was reached within $2 \mathrm{~h}$ for $160 \mathrm{mg} \mathrm{L}^{-1}$. While it takes 90 and $60 \mathrm{~min}$ to 
reach the equilibrium at initial creatinine concentrations 120 and $80 \mathrm{mg} \mathrm{L}^{-1}$, respectively. At initial concentration $160 \mathrm{mg} \mathrm{L}^{-1}$, the adsorption capacity $\mathrm{q}_{\mathrm{e}}$ at equilibrium is $40.3,42.6,42.8$ and $46.5 \mathrm{mg}$ $\mathrm{g}^{-1}$ for unmodified AC, 120-AC, 150-AC and 180-AC, respectively. It indicates that the adsorption capacity increased after nitric acid hydrothermal modification [24], which might due to the oxygen-containing functional groups such as strong carboxylic acids (-COOH), phenols (-OH) and carbonyls/quinones $(=\mathrm{O})$ generated by oxidation [34]. Similar to the trends for initial concentration at 120 and $80 \mathrm{mg} \mathrm{L}^{-1}, \mathrm{AC}$ modified by $4 \mathrm{M}$ nitric acid with $180{ }^{\circ} \mathrm{C}$ obtained the fastest adsorption speed and highest adsorption capacity for creatinine.

\subsection{Rate constant}

As is shown in Fig. S6, $\log \left(\mathrm{q}_{\mathrm{e}}-\mathrm{q}\right)$ versus $\mathrm{t}$ shows a poor agreement of experimental data with a first-order kinetic model with different initial creatinine concentrations $(80,120$ and 160 $\left.\mathrm{mg} \mathrm{L}^{-1}\right)$. This suggests the adsorption of creatinine onto AC sample is not a first-order reaction.

It can be seen from Fig. 3E, $\mathrm{G}$ and $\mathrm{I}$ that the plots of $\mathrm{t} / \mathrm{q}$ versus $\mathrm{t}$ show a linear relationship for each AC sample. The slops and intercepts of plots of $t / q$ versus $t$ were used to calculate the second-order rate constant $\mathrm{k}_{2}$ and $\mathrm{q}_{\mathrm{e}}$. The straight lines in plot of $\mathrm{t} / \mathrm{q}$ versus $\mathrm{t}$ (Fig. $3 \mathrm{E}, \mathrm{G}$ and $\mathrm{I}$ ) show a good agreement of experimental data with second-order kinetic model for different AC samples with different initial creatinine concentrations. Tables 4-6 list the calculated results obtained from the second-order kinetic model. The correlation coefficients for the second-order kinetic model, which are also presented in Tables 4-6, are higher than 0.99 for all the cases. These suggest that the adsorption of creatinine onto AC samples follows the second-order kinetic model and chemical adsorption might be the rate-limiting step [40]. Table 7 compares the adsorption capacity of different types of adsorbents used for removal of creatinine $[4,5,8]$. It can be seen the AC-180 has higher adsorption ability than that of most adsorbents reported in other literatures. 
Creatinine is one of the uraemic toxins in the blood, which is low molecular weight toxin. Some other middle molecular toxins could also be adsorbed by the active carbon during the adsorption. By comparing the adsorption capacities for the adsorption of creatinine onto various adsorbents such as carbon nanotube, zeolite, poly(ether sulfone)/activated carbon, it indicates that the surface functioned active carbon obtained by nitric acid hydrothermal modification get the highest adsorption capacity. Although the adsorption by AC is non-selective, it can potentially be employed to clinic application due to low cost without introducing any other substances into the blood [8]. Meanwhile, carbon filter and ion-exchange resin have been used to regenerate the adsorbent after dialysis [43]. Therefore, we are trying to develop new surface functioned AC adsorbents, and looking forward to collaborate with Sanford Healthcare to develop some real tests with clinic dialysis liquid samples, and consider competition from other biomolecules. In addition, one crucial factor impacting adsorption of creation by AC is the depletion of adsorption sites [44], competition and pore blockage during active carbon adsorption hampers the adsorption efficiency [45]. More work is needed to better understand how to optimize the adsorption of creatinine and other toxins in the blood.

\subsection{Mechanism of creatinine adsorption onto nitric acid modified AC}

There are two possible tautomers of creatinine, the imine 1 and amine 2 forms [46], as is shown in Fig. 3Ja. The amine 2 predominates in solution [47]. After $\mathrm{HNO}_{3}$ oxidation, some carboxylic acid groups were generated by the treatment as discussed above. Therefore, the amine (creatinine) and carboxylic acid reacted and formed covalent bond (Fig. 3Jb), the water produced and an amide was formed. This reaction enhanced the creatinine adsorption quantity by using the $\mathrm{HNO}_{3}$-modified ACs as sorbents. A hydrogen ion can break away from the phenolic group on the surface of the modified AC. The creatinine molecule combined with the hydrogen ion and was 
protonated $[6,48]$, which would be "adsorbed" by the negatively charged site from the previous phenolic group. This mechanism is shown in Fig. 3Jc, which indicates the pyridine-N-oxide structure was formed. The N1 spectra of AC-180 and creatinine-adsorbed AC-180 verified these formations.

Fig. 4 shows the deconvoluted N 1s spectra of 180-AC and creatinine adsorbed 180-AC. The N 1s spectra of these samples can be deconvoluted into different peaks centered at 399.7 (N1 component), 400.6 ( $\mathrm{N} 2$ component), 401.4 (N3 component), 403.0 ( $\mathrm{N} 4$ component), and $406.5 \mathrm{eV}$ (N5 component). According to the literature review, pyridinic-type nitrogen gives rise to a peak about $398.6 \mathrm{eV}$ [49], the binding energy of nitrogen in amides can be at about $399.7 \mathrm{eV}[50,51]$. Nitrogen in pyrrole and lactam groups was found to be at 400.3 [52] and $400.1 \mathrm{eV}$ [53], respectively. The contribution at $401.5 \mathrm{eV}$ has been assigned to various forms of quaternary nitrogen atoms [54]. Furthermore, the peak at $402-405 \mathrm{eV}$ was identified to arise from pyridine$\mathrm{N}$-oxide[55]. The higher binding energy around $406.5 \mathrm{eV}$ can be attributed to $\mathrm{N} 1 \mathrm{~s}$ of $-\mathrm{NO}_{2}$ [56]. Based on these literature reports, the N1 peak can be assigned to amide, and N2 peak to lactam and pyrrole groups. The N3 component can be assigned to highly coordinated nitrogen atoms bound to three $\mathrm{C}$ atoms in the bulk of a graphene layer and the $\mathrm{N} 4$ peak to the pyridine-N-oxide, which gives a peak above $402.0 \mathrm{eV}$ [57]. Finally, the $\mathrm{N} 5$ peak can be $\mathrm{NO}_{2}$ group on the modified AC. As is shown in Table 8, the total nitrogen concentration was increased from 0.74 to $2.58 \%$ after adsorption. To assess the amount of different types of $\mathrm{N}$-species, the relative percentage of different $\mathrm{N}$-groups was calculated based on the deconvoluted $\mathrm{N}$ 1s spectra (Table 8). AC-180 shows two peaks: a low binding energy component (N3) centered at $401.4 \mathrm{eV}$ and a higher binding energy component (N5) centered at $406.5 \mathrm{eV}$. In case of creatinine adsorbed 180-AC, three other peaks (N1, N2 and N4) appeared. It indicates that nitrogen component N1 increased $0.91 \%$, which 
agrees with the amide formed in Fig. 3Jb. The N2 species and the increased amount of N3 species of creatinine adsorbed 180-AC, which may come from the creatinine itself. N4-type-nitrogen species $(0.15 \%)$ was from the pyridine-N-oxide formed according to the combination shown in Fig. 3Jc. While the N5 component remained the same after the adsorption since there was no reaction to the $-\mathrm{NO}_{2}$ group during the adsorption. The carboxyl and phenolic groups generated by $\mathrm{HNO}_{3}$ oxidation combined with the creatinine molecules, therefore, the creatinine adsorption capacity increased after $\mathrm{HNO}_{3}$ treatment.

\subsection{Conclusions}

After $4 \mathrm{M} \mathrm{HNO}_{3}$ hydrothermal modification at $180{ }^{\circ} \mathrm{C}$, the total surface oxygen content was increased 2.69 times. Although the BET surface area was decreased by $26 \mathrm{~m}^{2} \mathrm{~g}^{-1}$, the creatinine saturation adsorption capacity in 180 -AC was $29 \%$ higher than the unmodified AC. The improvement of the adsorptive performance by the $\mathrm{HNO}_{3}$ oxidation modification is dominantly through an increase of the oxygen-containing functional groups on the AC surface. N 1s XPS results indicate carboxyl and phenolic groups generated by $\mathrm{HNO}_{3}$ oxidation can potentially “adsorb" (reacted with) creatinine. Freundlich model and second-order kinetic model fitted very well to the equilibrium isotherm and the dynamical behavior for the adsorption of creatinine onto the $\mathrm{HNO}_{3}$-modified ACs. These suggested that the rate-limiting step might be chemical adsorption but not mass transfer.

\section{Acknowledgements}

This research was funded by following projects: 1) "Development of high value carbon based adsorbents from thermochemically produced biochar" USDA-NIFA 2011-67009-20030 through the USDA-NIFA Agriculture and Food Research Initiative Sustainable Bioenergy Program which 
funded the Micropore analyzer and instruments for modifying AC; 2) NSF EPSCoR Track II Dakota BioCon center (National Science Foundation/EPSCoR Award No. 1330842) supported Mr. Cao Yuhe for his PhD study; 3) DOE Sun Grant Concept Project "Developing Gas Stripping Adsorption/Desorption Separation Processes based on Porous Carbon Adsorbents for Biofuel Purification from Bioreactors" (North Central Sun Grant Award No. 1300478) supported upgrading the Chemical Adsorption Analyzer. The authors would like to acknowledge use of the University of Iowa Central Microscopy Research Facility, a core resource supported by the Vice President for Research \& Economic Development, the Holden Comprehensive Cancer Center and the Carver College of Medicine. 


\section{References}

[1] Panasyuk-Delaney T, Mirsky VM, Wolfbeis OS. Capacitive Creatinine Sensor Based on a Photografted Molecularly Imprinted Polymer. Electroanal. 2002;14:221-4.

[2] Yushin G, Hoffman EN, Barsoum MW, Gogotsi Y, Howell CA, Sandeman SR, et al. Mesoporous carbide-derived carbon with porosity tuned for efficient adsorption of cytokines. Biomaterials. 2006;27:5755-62.

[3] Malik DJ, Warwick GL, Venturi M, Streat M, Hellgardt K, Hoenich N, et al. Preparation of novel mesoporous carbons for the adsorption of an inflammatory cytokine (IL-1 beta).

Biomaterials. 2004;25:2933-40.

[4] Deng X, Wang T, Zhao F, Li L, Zhao C. Poly(ether sulfone)/activated carbon hybrid beads for creatinine adsorption. J Appl Polym Sci. 2007;103:1085-92.

[5] Wernert V, Schäf O, Ghobarkar H, Denoyel R. Adsorption properties of zeolites for artificial kidney applications. Microporous Mesoporous Mater. 2005;83:101-13.

[6] Bergé-Lefranc D, Pizzala H, Denoyel R, Hornebecq V, Bergé-Lefranc J-L, Guieu R, et al. Mechanism of creatinine adsorption from physiological solutions onto mordenite. Microporous Mesoporous Mater. 2009;119:186-92.

[7] Bergé-Lefranc D, Schäf O, Denoyel R, Bergé-Lefranc J-L, Guieu R, Brunet P, et al. The extraction of creatinine from a physiological medium by a microporous solid and its quantification by diffuse reflectance UV spectroscopy. Microporous Mesoporous Mater. 2010;129:144-8.

[8] Ye C, Gong Q, Lu F, Liang J. Adsorption of uraemic toxins on carbon nanotubes. Sep Purif Technol. 2007;58:2-6. 
[9] Tsai HA, Syu MJ. Synthesis of creatinine-imprinted poly(beta-cyclodextrin) for the specific binding of creatinine. Biomaterials. 2005;26:2759-66.

[10] Tsai H-A, Syu M-J. Synthesis and characterization of creatinine imprinted poly(4vinylpyridine-co-divinylbenzene) as a specific recognition receptor. Anal Chim Acta. 2005;539:107-16.

[11] Chang Y-S, Ko T-H, Hsu T-J, Syu M-J. Synthesis of an Imprinted Hybrid Organic-Inorganic Polymeric Sol-Gel Matrix Toward the Specific Binding and Isotherm Kinetics Investigation of Creatinine. Anal Chem. 2009;81:2098-105.

[12] Yang C-X, Liu C, Cao Y-M, Yan X-P. Metal-organic framework MIL-100(Fe) for artificial kidney application. RSC Adv. 2014;4:40824-7.

[13] Mydlík M, Buček J, Derzsiová K, Jarčuška J, Takáč M. Influence of charcoal haemoperfusion on platelet count in acute poisoning and during regular dialysis treatment. Int Urol Nephrol. 1981;13:387-9.

[14] Winchester JF, Silberzweig J, Ronco C, Kuntsevich V, Levine D, Parker T, et al. Sorbents in acute renal failure and end-stage renal disease: middle molecule and cytokine removal. Blood Purif. 2004;22:73-7.

[15] Ash SR, Sullivan TA, Carr DJ. Sorbent Suspensions vs. Sorbent Columns for Extracorporeal Detoxification in Hepatic Failure. Ther Apher Dial. 2006;10:145-53.

[16] Sandeman SR, Howell CA, Phillips GJ, Lloyd AW, Davies JG, Mikhalovsky SV, et al. Assessing the in vitro biocompatibility of a novel carbon device for the treatment of sepsis. Biomaterials. 2005;26:7124-31.

[17] Yu J, Wu Y, Wang S, Ma X. The preparation of cellulose nitrate derivatives and their adsorption properties for creatinine. Carbohydr Polym. 2007;70:8-14. 
[18] Friedman EA. Bowel as a kidney substitute in renal failure. Am J Kidney Dis. 1996;28:94350.

[19] Brunori G, Viola BF, Maiorca P, Cancarini G. How to Manage Elderly Patients with Chronic Renal Failure: Conservative Management versus Dialysis. Blood Purif. 2008;26:36-40. [20] Soudani N, Souissi-najar S, Ouederni A. Influence of Nitric Acid Concentration on Characteristics of Olive Stone Based Activated Carbon. Chin J Chem Eng. 2013;21:1425-30. [21] Zhou A, Ma X, Song C. Effects of oxidative modification of carbon surface on the adsorption of sulfur compounds in diesel fuel. Appl Catal, B. 2009;87:190-9.

[22] Cao Y, Wang K, Wang X, Gu Z, Gibbons W, Vu H. Adsorption of butanol vapor on active carbons with nitric acid hydrothermal modification. Bioresour Technol. 2015;196:525-32.

[23] Cao Y, Wang K, Wang X, Gu Z, Gibbons W, Vu H. Butanol vapor adsorption behavior on active carbons and zeolite crystal. Appl Surf Sci. 2015;349:1-7.

[24] Liang ZP, Feng YQ, Meng SX, Liang ZY. Equilibrium and kinetic modeling of adsorption of urea nitrogen onto chitosan coated dialdehyde cellulose. Process Biochem. 2005;40:3218-24. [25] Brunauer S, Deming LS, Deming WE, Teller E. On a Theory of the van der Waals Adsorption of Gases. J Am Chem Soc. 1940;62:1723-32.

[26] Wang Q, Liang X, Qiao W, Liu C, Liu X, Zhang R, et al. Modification of polystyrene-based activated carbon spheres to improve adsorption of dibenzothiophene. Appl Surf Sci. 2009;255:3499-506.

[27] Zhuang QL, Kyotani T, Tomita A. The change of TPD pattern of O2-gasified carbon upon air exposure. Carbon. 1994;32:539-40.

[28] Zielke U, Hüttinger KJ, Hoffman WP. Surface-oxidized carbon fibers: I. Surface structure and chemistry. Carbon. 1996;34:983-98. 
[29] Marchon B, Carrazza J, Heinemann H, Somorjai GA. TPD and XPS studies of O2, CO2, and $\mathrm{H} 2 \mathrm{O}$ adsorption on clean polycrystalline graphite. Carbon. 1988;26:507-14.

[30] Figueiredo JL, Pereira MFR, Freitas MMA, Órfão JJM. Modification of the surface chemistry of activated carbons. Carbon. 1999;37:1379-89.

[31] Ruta M, Semagina N, Kiwi-Minsker L. Monodispersed Pd Nanoparticles for Acetylene Selective Hydrogenation: Particle Size and Support Effects. J Phys Chem C. 2008;112:13635-41. [32] Tribolet P, Kiwi-Minsker L. Palladium on carbon nanofibers grown on metallic filters as novel structured catalyst. Catal Today. 2005;105:337-43.

[33] Langley LA, Villanueva DE, Fairbrother DH. Quantification of Surface Oxides on Carbonaceous Materials. Chem Mater. 2005;18:169-78.

[34] Silva AMT, Machado BF, Figueiredo JL, Faria JL. Controlling the surface chemistry of carbon xerogels using HNO3-hydrothermal oxidation. Carbon. 2009;47:1670-9.

[35] Wang ZM, Yamashita N, Wang ZX, Hoshinoo K, Kanoh H. Air oxidation effects on microporosity, surface property, and $\mathrm{CH} 4$ adsorptivity of pitch-based activated carbon fibers. J Colloid Interface Sci. 2004;276:143-50.

[36] Zhou A, Ma X, Song C. Liquid-phase adsorption of multi-ring thiophenic sulfur compounds on carbon materials with different surface properties. J Phys Chem B. 2006;110:4699-707. [37] Guedidi H, Reinert L, Lévêque J-M, Soneda Y, Bellakhal N, Duclaux L. The effects of the surface oxidation of activated carbon, the solution $\mathrm{pH}$ and the temperature on adsorption of ibuprofen. Carbon. 2013;54:432-43.

[38] Wang Y-Q, Viswanathan H, Audi AA, Sherwood PM. X-ray photoelectron spectroscopic studies of carbon fiber surfaces. 22. Comparison between surface treatment of untreated and previously surface-treated fibers. Chem Mater. 2000;12:1100-7. 
[39] Zhang Y, Cheng Y, Chen N, Zhou Y, Li B, Gu W, et al. Recyclable removal of bisphenol A from aqueous solution by reduced graphene oxide-magnetic nanoparticles: adsorption and desorption. Journal of colloid and interface science. 2014;421:85-92.

[40] Kong W, Dai Q, Ren J, Ma N. Homogeneous acylation of xylan with 3,5-dinitrobenzoyl in ionic liquid and the adsorption property. Carbohydr Polym. 2015;128:105-11.

[41] Tseng RL, Wu FC. Inferring the favorable adsorption level and the concurrent multi-stage process with the Freundlich constant. Journal of hazardous materials. 2008;155:277-87.

[42] Ahalya N, Kanamadi RD, Ramachandra TV. Biosorption of chromium (VI) from aqueous solutions by the husk of Bengal gram (Cicer arientinum). Electronic Journal of Biotechnology. 2005;8:258-64.

[43] Bellmann R, Graziadei IW, Feistritzer C, Schwaighofer H, Stellaard F, Sturm E, et al. Treatment of refractory cholestatic pruritus after liver transplantation with albumin dialysis. Liver transplantation : official publication of the American Association for the Study of Liver Diseases and the International Liver Transplantation Society. 2004;10:107-14.

[44] Hu J, Shang R, Heijman B, Rietveld L. Influence of activated carbon preloading by EfOM fractions from treated wastewater on adsorption of pharmaceutically active compounds. Chemosphere. 2016;150:49-56.

[45] Hu J, Martin A, Shang R, Siegers W, Cornelissen E, Heijman B, et al. Anionic exchange for NOM removal and the effects on micropollutant adsorption competition on activated carbon. Separation and Purification Technology. 2014;129:25-31.

[46] Simon Craw J, D. Cooper M, H. Hillier I. The structure and intermolecular interactions of a creatinine designed-receptor complex, studied by ab initio methods. J Chem Soc, Perkin Trans 2. 1997:869-72. 
[47] Bell T, Hou Z, Luo Y, Drew M. Detection of creatinine by a designed receptor. Science. 1995;269:671.

[48] Reddick RE, Kenyon GL. Syntheses and NMR studies of specifically labeled [215N]phosphocreatine, [2-15N]creatinine, and related 15N-labeled compounds. J Am Chem Soc. $1987 ; 109: 4380-7$.

[49] Szymański GS, Grzybek T, Papp H. Influence of nitrogen surface functionalities on the catalytic activity of activated carbon in low temperature SCR of NOx with NH3. Catal Today. 2004;90:51-9.

[50] Lahaye J, Nanse G, Bagreev A, Strelko V. Porous structure and surface chemistry of nitrogen containing carbons from polymers. Carbon. 1999;37:585-90.

[51] Radovic L, Silva I, Ume J, Menendez J, Leon CLY, Scaroni A. An experimental and theoretical study of the adsorption of aromatics possessing electron-withdrawing and electrondonating functional groups by chemically modified activated carbons. Carbon. 1997;35:1339-48. [52] Meldrum BJ, Rochester CH. In situ infrared study of the modification of the surface of activated carbon by ammonia, water and hydrogen. J Chem Soc, Faraday Trans. 1990;86:1881-4. [53] Liu K, Suzuki Y, Fukuda Y. Surface analysis of (NH2) 2CS-treated GaP (001) by AES and XPS. Surf Interface Anal. 2004;36:966-8.

[54] Pels J, Kapteijn F, Moulijn J, Zhu Q, Thomas K. Evolution of nitrogen functionalities in carbonaceous materials during pyrolysis. Carbon. 1995;33:1641-53.

[55] Wang H, Côté R, Faubert G, Guay D, Dodelet JP. Effect of the Pre-Treatment of Carbon Black Supports on the Activity of Fe-Based Electrocatalysts for the Reduction of Oxygen. J Phys Chem B. 1999;103:2042-9. 
[56] Pan Q, Wang H, Jiang Y. Natural graphite modified with nitrophenyl multilayers as anode materials for lithium ion batteries. J Mater Chem. 2007;17:329-34.

[57] Golzhauser A, Woll C. Interfacial systems chemistry: out of the vacuum--through the liquid--into the cell. Phys Chem Chem Phys. 2010;12:4273-4. 


\section{Figure captions}

Fig. 1. (A) $\mathrm{N}_{2}$ adsorption-desorption isotherms of ACs; (B) DFT pore size distribution curves of the absorbents; (C) Cumulative pore volumes of the absorbents; (D) TPD profiles of ACs.

Fig. 2. (A) C 1s and (B) O 1s XPS spectra of (a) unmodified AC, (b) 180-AC.

Fig. 3. (A) Equilibrium adsorptions of creatinine onto AC samples; (B) Saturation adsorption capacities of creatinine at $160 \mathrm{mg} \mathrm{L}^{-1}$; (C) Freundlich plots for AC samples; Adsorption kinetics

of different initial creatinine concentrations: (D) $160 \mathrm{mg} \mathrm{L}^{-1}$; (F) $120 \mathrm{mg} \mathrm{L}^{-1}$; (H) $80 \mathrm{mg} \mathrm{L}^{-1}$. Plots of pseudo second-order model of different initial creatinine concentrations: (E) $160 \mathrm{mg} \mathrm{L}^{-1}$; (G) $120 \mathrm{mg} \mathrm{L}^{-1}$; (I) $80 \mathrm{mg} \mathrm{L}^{-1}$. (J) Tautomers of creatinine and possible reactions between $\mathrm{HNO}_{3}$ modified AC and creatinine.

Fig. 4. N 1s XPS spectra of (a) 180-AC, (b) creatinine adsorbed 180-AC. 
A

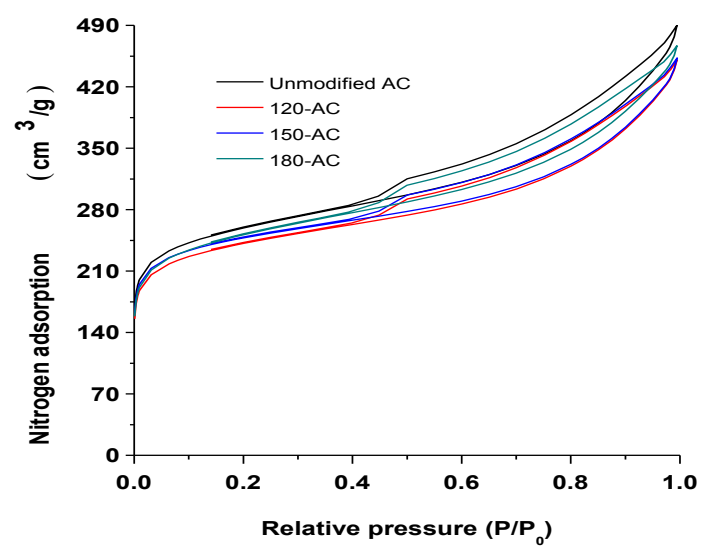

$\mathrm{C}$

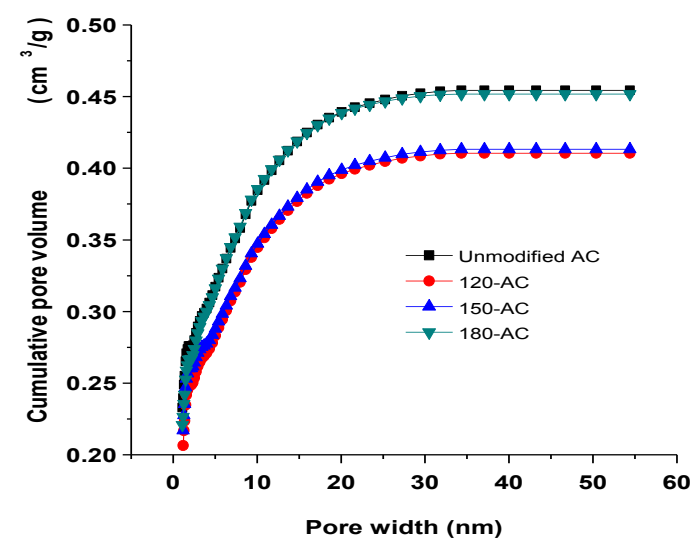

B

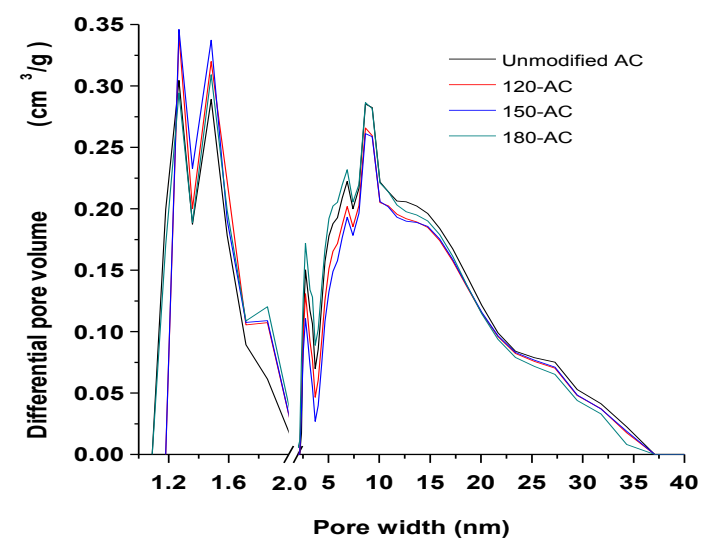

$\mathrm{D}$

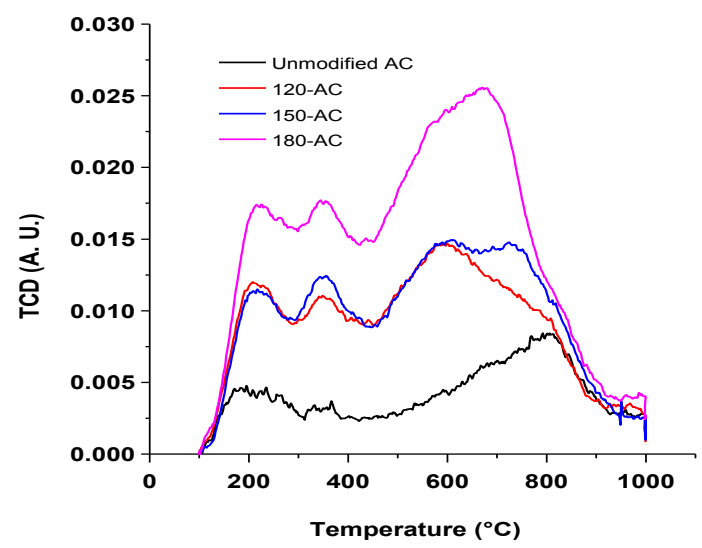

Fig. 1. (A) $\mathrm{N}_{2}$ adsorption-desorption isotherms of ACs; (B) DFT pore size distribution curves of the absorbents; (C) Cumulative pore volumes of the absorbents; (D) TPD profiles of ACs. 
A
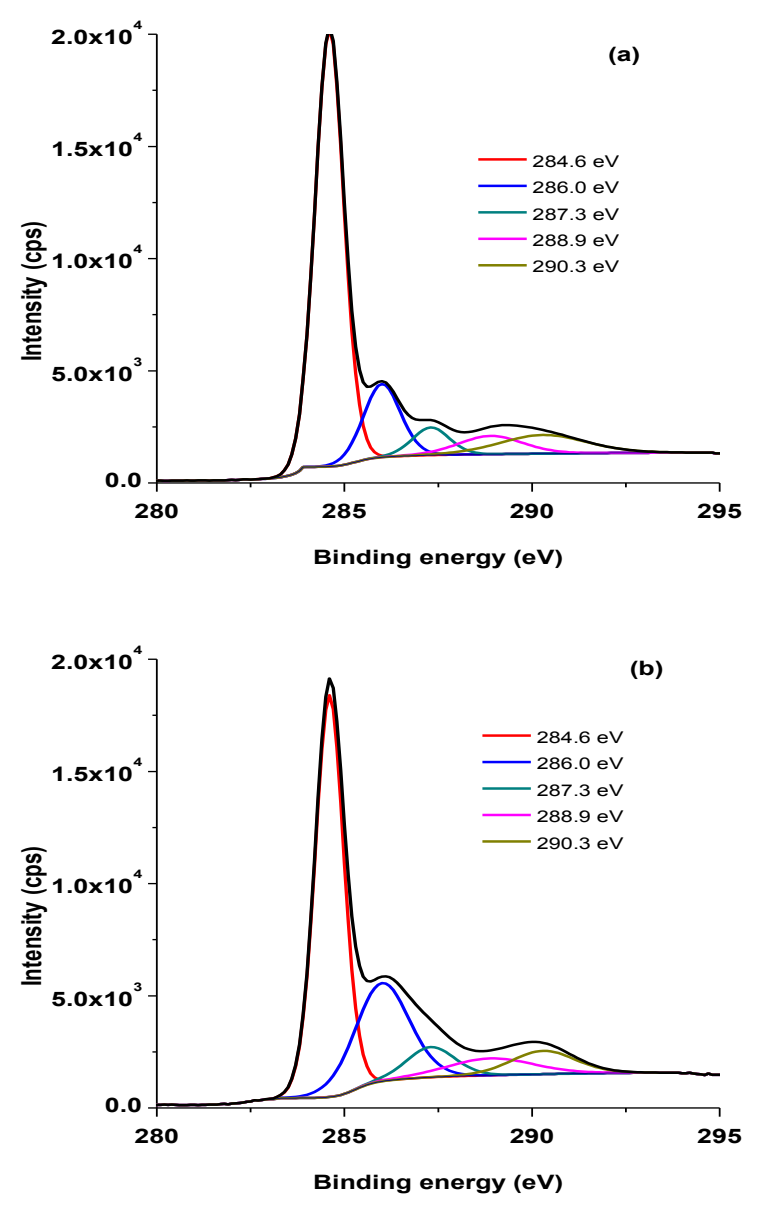

B
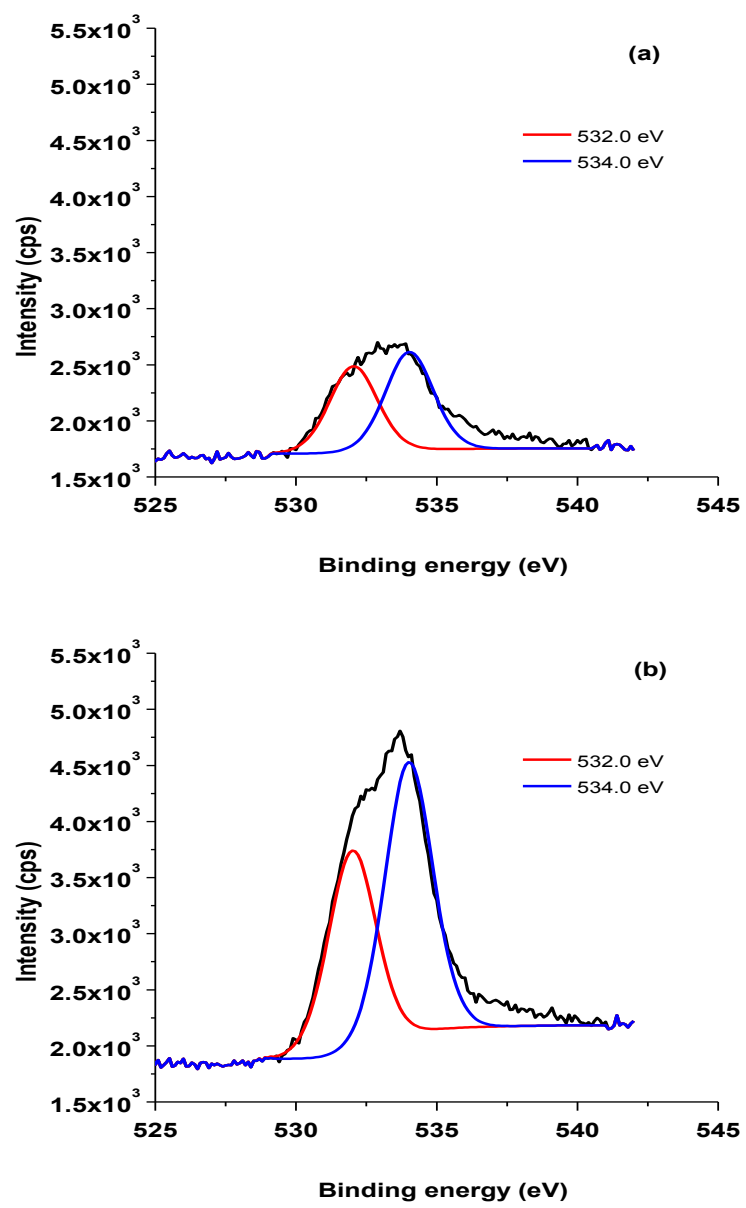

Fig. 2. (A) C 1s and (B) O 1s XPS spectra of (a) unmodified AC, (b) 180-AC. 
A

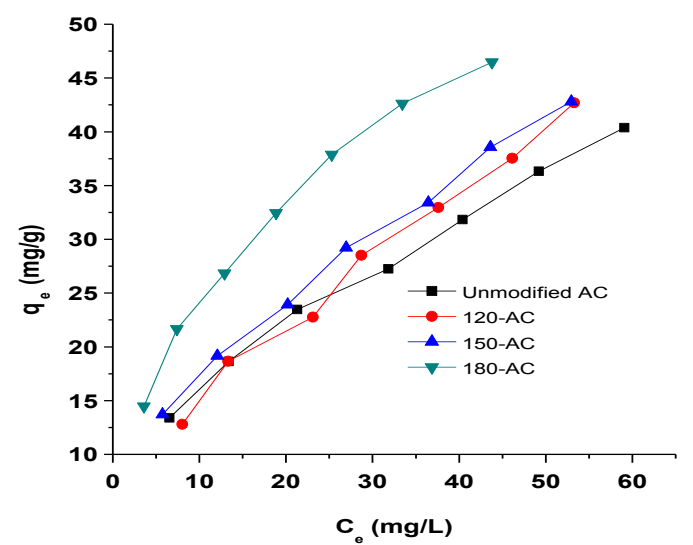

C

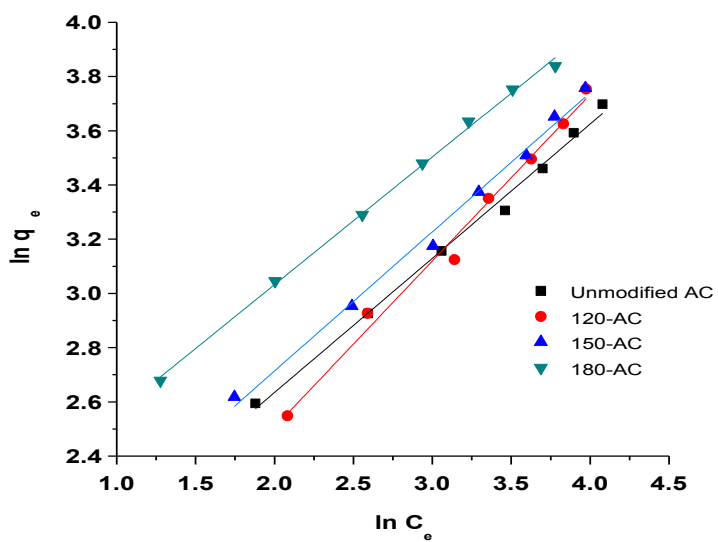

E

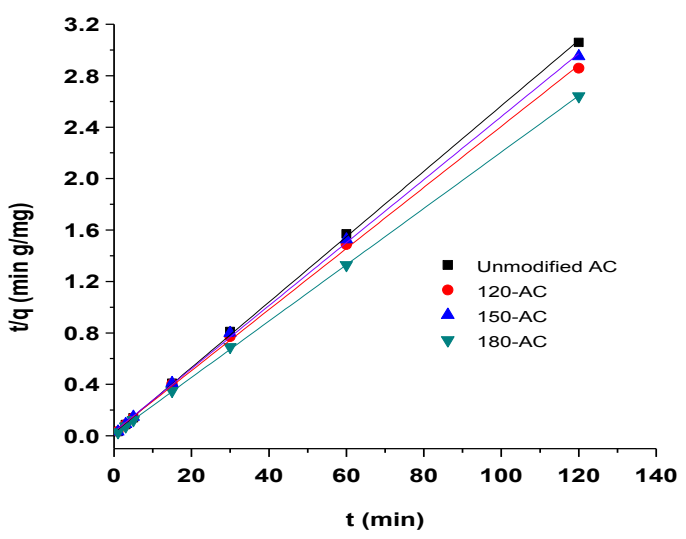

B

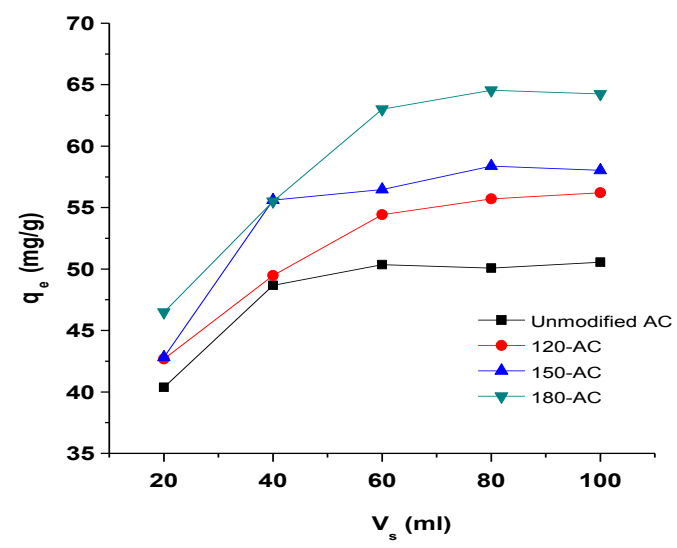

D

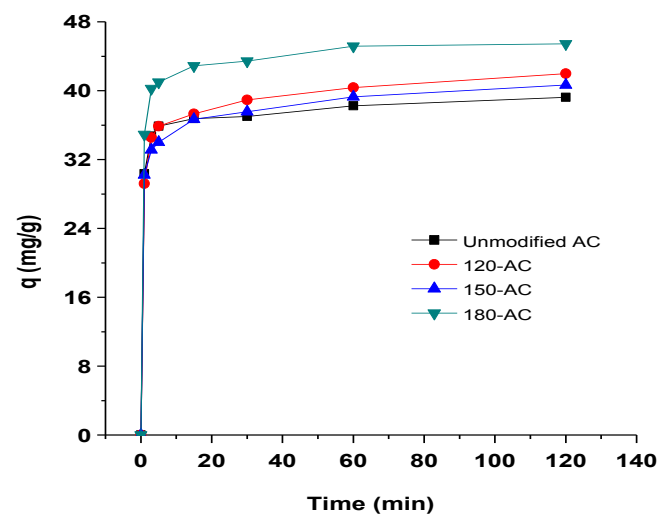

F

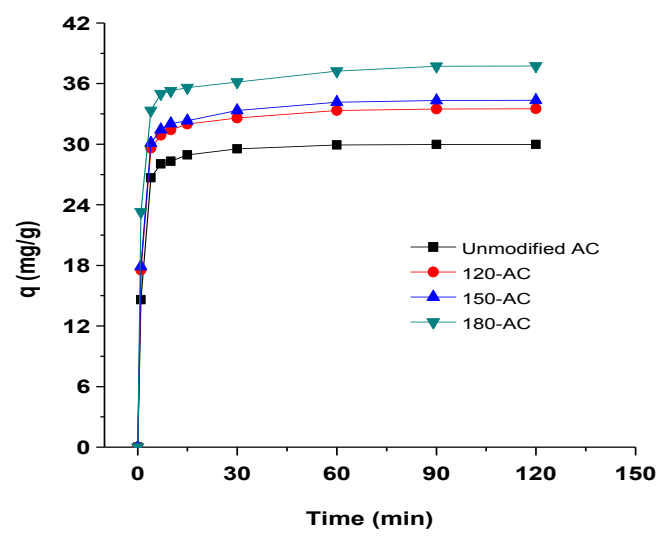


G

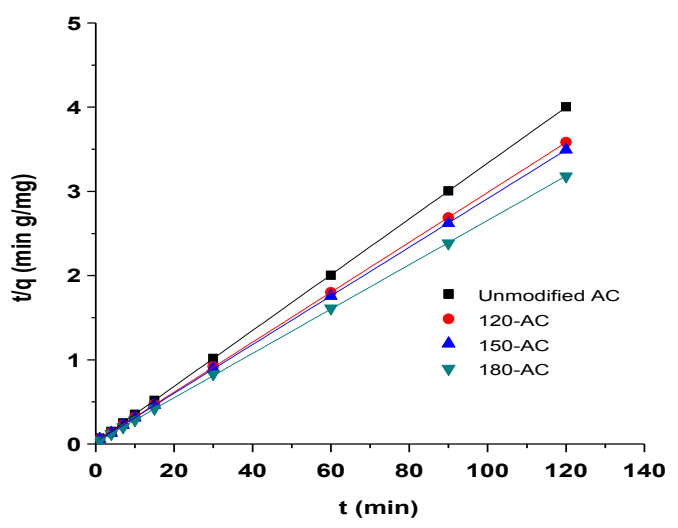

I

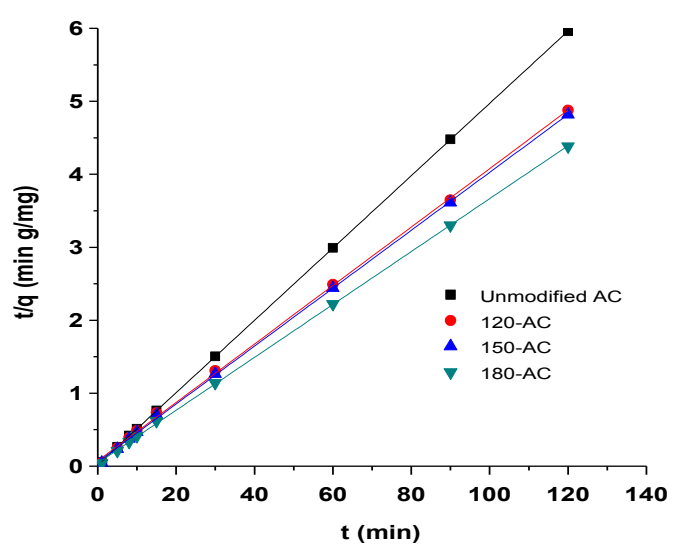

$\mathrm{H}$

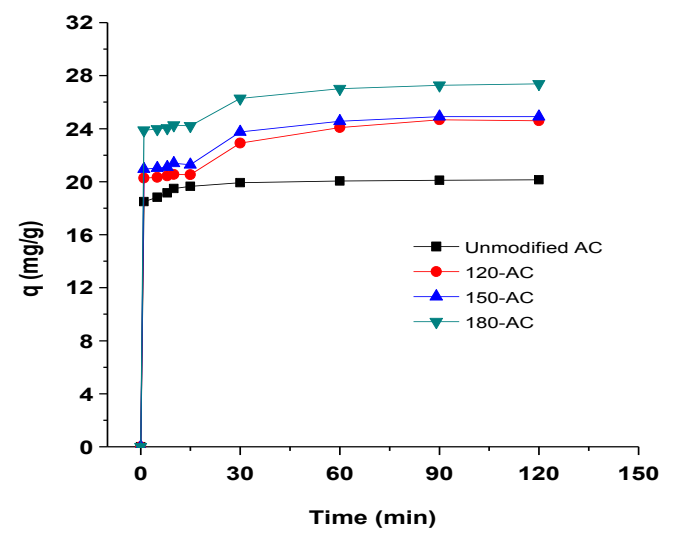

$\mathrm{J}$<smiles>CCn1c(=O)nc(N)n1C</smiles>

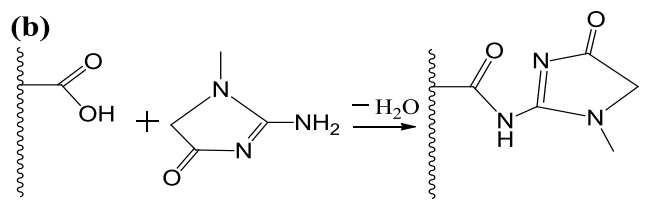

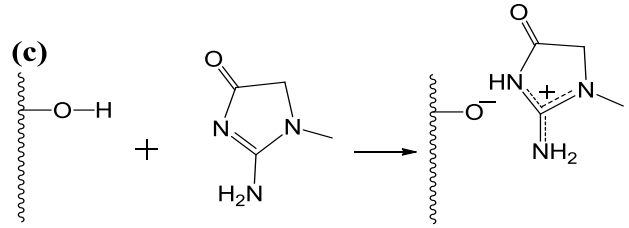

Fig. 3. (A) Equilibrium adsorptions of creatinine onto AC samples; (B) Saturation adsorption capacities of creatinine at $160 \mathrm{mg} \mathrm{L}^{-1}$; (C) Freundlich plots for AC samples. Adsorption kinetics of different initial creatinine concentrations: (D) $160 \mathrm{mg} \mathrm{L}^{-1}$; (F) $120 \mathrm{mg} \mathrm{L}^{-1}$; (H) $80 \mathrm{mg} \mathrm{L}^{-1}$. Plots of pseudo second-order model of different initial creatinine concentrations: (E) $160 \mathrm{mg} \mathrm{L}^{-1}$; (G) $120 \mathrm{mg} \mathrm{L}^{-1}$; (I) $80 \mathrm{mg} \mathrm{L}^{-1}$. (J) Tautomers of creatinine and possible reactions between $\mathrm{HNO}_{3}$ modified $\mathrm{AC}$ and creatinine. 

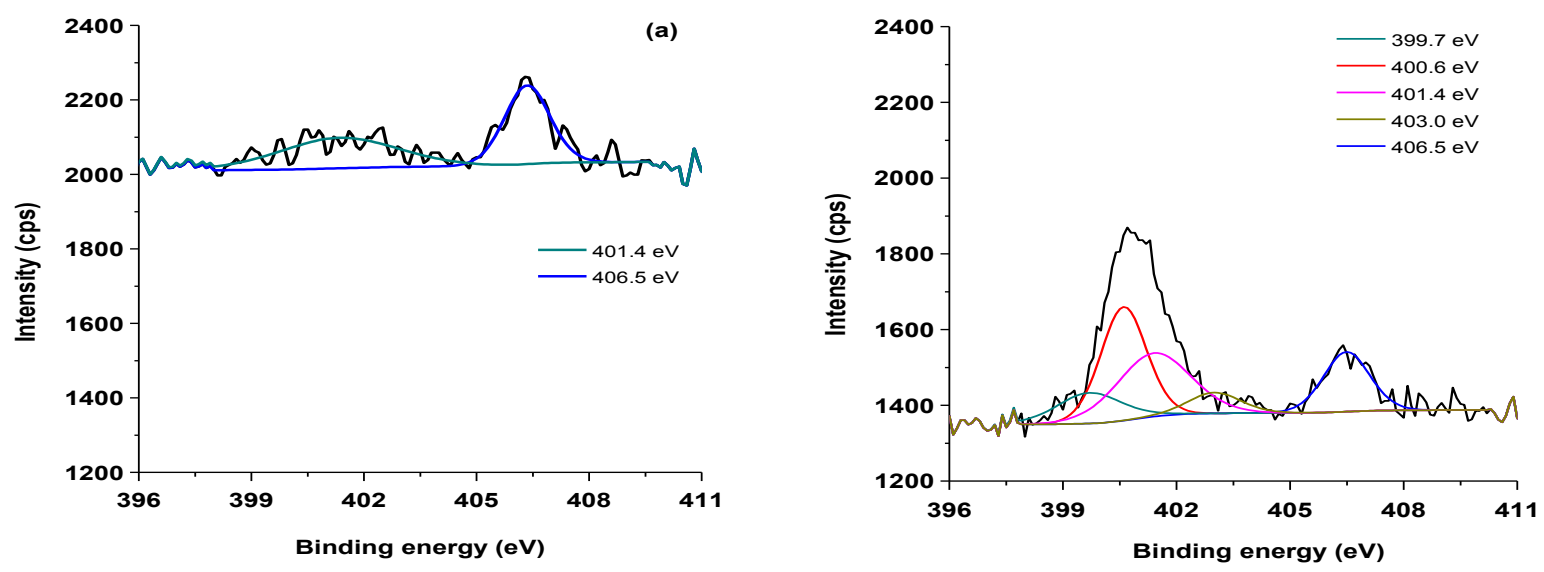

Fig. 4. N 1s XPS spectra of (a) 180-AC, (b) creatinine adsorbed 180-AC. 


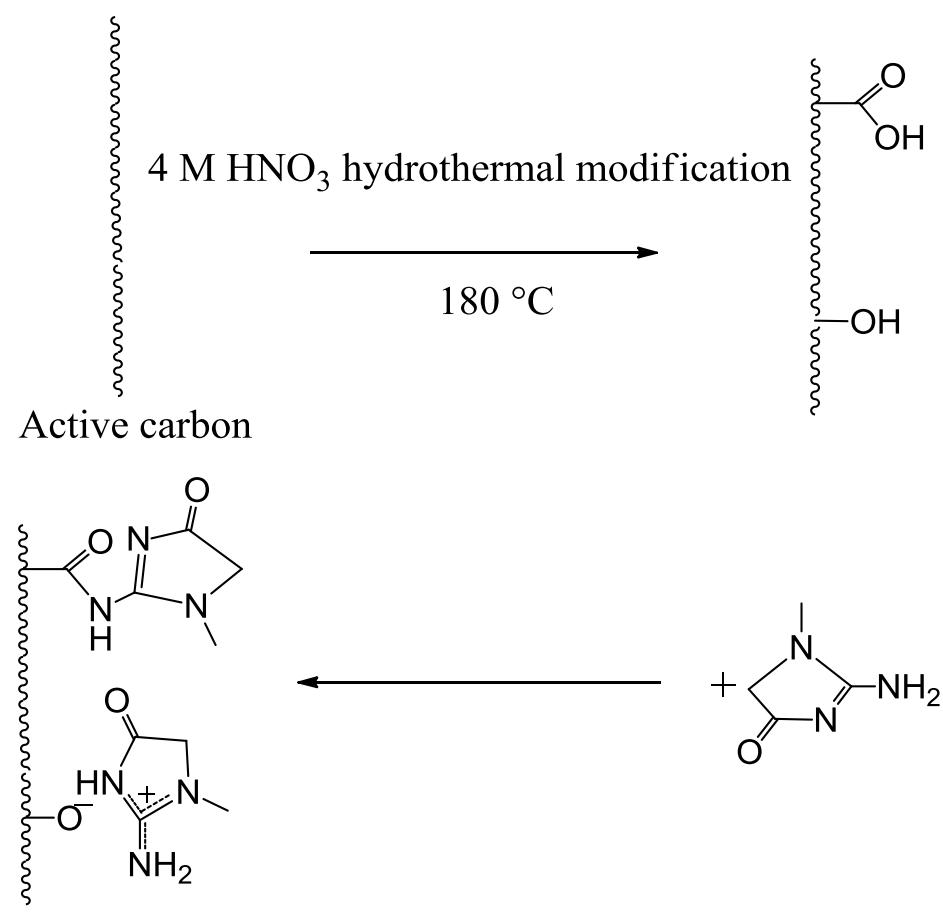




\section{Table caption}

Table 1 Surface area and pore structure parameters of the absorbents.

Table 2. Surface functional group molar ratio distributions obtained by XPS measurement.

Table 3. The parameters of Langmuir adsorption isotherm model and the Freundlich adsorption isotherm model.

Table 4. The parameters of second-order adsorption rate constants and calculated $\mathrm{q}_{\mathrm{e}}$ for different AC samples at initial concentration $(160 \mathrm{mg} / \mathrm{L})$.

Table 5. The parameters of second-order adsorption rate constants and calculated $\mathrm{q}_{\mathrm{e}}$ for different AC samples at initial concentration $(120 \mathrm{mg} / \mathrm{L})$.

Table 6. The parameters of second-order adsorption rate constants and calculated $\mathrm{q}_{\mathrm{e}}$ for different AC samples at initial concentration $(80 \mathrm{mg} / \mathrm{L})$.

Table 7. Adsorption capacities for the adsorption of creatinine onto various adsorbents.

Table 8. Surface nitrogen composition of AC-180 and creatinine adsorbed 180-AC derived from XPS. 
Table 1 Surface area and pore structure parameters of the absorbents.

\begin{tabular}{crrrrc}
\hline Sample \# & $\begin{array}{c}\mathrm{S}_{\mathrm{BET}^{\mathrm{a}}} \\
\mathrm{m}^{2} \mathrm{~g}^{-1}\end{array}$ & $\begin{array}{c}\mathrm{V}_{\text {Total }}{ }^{\mathrm{b}} \\
\mathrm{cm}^{3} \mathrm{~g}^{-1}\end{array}$ & $\begin{array}{c}\mathrm{V}_{\text {Micro }}{ }^{\mathrm{c}} \\
\mathrm{cm}^{3} \mathrm{~g}^{-1}\end{array}$ & $\begin{array}{c}\mathrm{V}_{\text {Meso }}{ }^{\mathrm{d}} \\
\mathrm{cm}^{3} \mathrm{~g}^{-1}\end{array}$ & $\begin{array}{c}\mathrm{D}_{\text {Average }} \mathrm{e}^{\mathrm{e}} \\
\mathrm{nm}\end{array}$ \\
\hline $\begin{array}{c}\text { Unmodified AC } \\
\text { 120-AC }\end{array}$ & 909 & 0.76 & 0.28 & 0.17 & 3.34 \\
150-AC & 847 & 0.70 & 0.25 & 0.16 & 3.31 \\
180-AC & 889 & 0.70 & 0.26 & 0.15 & 3.22 \\
\hline
\end{tabular}

${ }^{\text {a }}$ BET (Brunauer-Emmett-Teller) surface area

${ }^{\mathrm{b}}$ Total pore volume, measured at $\mathrm{P} / \mathrm{P}_{0}=0.995$

${ }^{\mathrm{c}}$ Micropore volume, based on density functional theory (DFT)

${ }^{\mathrm{d}}$ Mesopore volume, based on density functional theory (DFT)

${ }^{\mathrm{e}}$ Average pore diameter of absorbents, calculated by $4 \mathrm{~V}_{\text {Total }} / \mathrm{S}_{\mathrm{BET}}$

Table 2. Surface functional group molar ratio distributions obtained by XPS measurement.

\begin{tabular}{lccccccc}
\hline Sample & $\mathrm{C} 1 \mathrm{~s}$ & & & & & $\mathrm{O} 1 \mathrm{~s}$ \\
\cline { 2 - 8 } & $\mathrm{C}=\mathrm{C}$ & $\mathrm{C}-\mathrm{O}$ & $\mathrm{C}=\mathrm{O}$ & $\mathrm{O}-\mathrm{C}=\mathrm{O}$ & $\mathrm{CO}_{3}$ & $=\mathrm{O}$ & $-\mathrm{O}-$ \\
\hline Unmodified AC & 87.47 & 5.21 & 1.96 & 2.25 & 3.10 & 1.88 & 2.15 \\
180-AC & 81.06 & 10.41 & 2.81 & 2.81 & 2.90 & 4.17 & 5.67 \\
\hline
\end{tabular}

Table 3. The parameters of Langmuir adsorption isotherm model and the Freundlich adsorption isotherm model.

\begin{tabular}{lcccccc}
\hline \multirow{2}{*}{ Samples } & \multicolumn{2}{l}{ Langmuir } & \multicolumn{4}{l}{ Freundlich } \\
\cline { 2 - 7 } & $\mathrm{R}^{2}$ & $\mathrm{Q}\left(\mathrm{mg} \mathrm{g}^{-1}\right)$ & $\mathrm{b}\left(\mathrm{L} \mathrm{mg}^{-1}\right)$ & $\mathrm{R}^{2}$ & $\mathrm{n}$ & $\mathrm{k}_{\mathrm{f}}(\mathrm{mg} / \mathrm{g})\left(\mathrm{dm}^{3} / \mathrm{mg}\right)^{1 / \mathrm{n}}$ \\
\hline Unmodified AC & 0.9422 & 55.6 & 0.0379 & 0.9936 & 2.02 & 5.18 \\
120-AC & 0.9070 & 71.4 & 0.0243 & 0.9870 & 1.63 & 3.59 \\
150-AC & 0.9335 & 62.5 & 0.0376 & 0.9919 & 1.95 & 5.41 \\
180-AC & 0.9830 & 62.5 & 0.0690 & 0.9977 & 2.12 & 8.09 \\
\hline
\end{tabular}

Table 4. The parameters of second-order adsorption rate constants and calculated $\mathrm{q}_{\mathrm{e}}$ for different AC samples at initial concentration $(160 \mathrm{mg} / \mathrm{L})$.

\begin{tabular}{llll}
\hline Samples & \multicolumn{3}{l}{ Second-order kinetic model } \\
\cline { 2 - 4 } & $\mathrm{k}_{2}\left(\mathrm{~g} \mathrm{mg}^{-1} \mathrm{~min}^{-1}\right)$ & $\mathrm{q}_{\mathrm{e}, \mathrm{cal}}\left(\mathrm{mg} \mathrm{g}^{-1}\right)$ & $\mathrm{R}^{2}$ \\
\hline Unmodified AC & $2.976 \mathrm{E}-2$ & 40.0 & 0.9997 \\
120-AC & $1.707 \mathrm{E}-2$ & 43.5 & 0.9990 \\
150-AC & $1.858 \mathrm{E}-2$ & 41.7 & 0.9995 \\
$180-\mathrm{AC}$ & $2.940 \mathrm{E}-2$ & 47.6 & 0.9990 \\
\hline
\end{tabular}


Table 5. The parameters of second-order adsorption rate constants and calculated $\mathrm{q}_{\mathrm{e}}$ for different AC samples at initial concentration $(120 \mathrm{mg} / \mathrm{L})$.

\begin{tabular}{llll}
\hline Samples & \multicolumn{3}{l}{ Second-order kinetic model } \\
\cline { 2 - 4 } & $\mathrm{k}_{2}\left(\mathrm{~g} \mathrm{mg}^{-1} \mathrm{~min}^{-1}\right)$ & $\mathrm{q}_{\mathrm{e}, \mathrm{cal}}\left(\mathrm{mg} \mathrm{g}^{-1}\right)$ & $\mathrm{R}^{2}$ \\
\hline Unmodified AC & 20.08 & 30.2 & 0.9999 \\
120-AC & 25.79 & 33.8 & 0.9999 \\
150-AC & 29.09 & 34.6 & 0.9999 \\
180-AC & 31.51 & 38.0 & 0.9999 \\
\hline
\end{tabular}

Table 6. The parameters of second-order adsorption rate constants and calculated $\mathrm{q}_{\mathrm{e}}$ for different AC samples at initial concentration $(80 \mathrm{mg} / \mathrm{L})$.

\begin{tabular}{llll}
\hline Samples & \multicolumn{3}{l}{ Second-order kinetic model } \\
\cline { 2 - 4 } & $\mathrm{k}_{2}\left(\mathrm{~g} \mathrm{mg}^{-1} \mathrm{~min}^{-1}\right)$ & $\mathrm{q}_{\mathrm{e}, \mathrm{cal}}\left(\mathrm{mg} \mathrm{g}^{-1}\right)$ & $\mathrm{R}^{2}$ \\
\hline Unmodified AC & 6.83 & 20.2 & 0.9999 \\
120-AC & 45.20 & 25.0 & 0.9994 \\
150-AC & 37.08 & 25.2 & 0.9997 \\
180-AC & 31.66 & 27.6 & 0.9998 \\
\hline
\end{tabular}

Table 7. Adsorption capacities for the adsorption of creatinine onto various adsorbents.

\begin{tabular}{lcc}
\hline Adsorbent & Adsorption capacity $\left(\mathrm{mg} \mathrm{g}^{-1}\right)$ & Reference \\
\hline AC-180 & 64.5 & This work \\
Poly(ether sulfone)/activated carbon & 28.0 & {$[4]$} \\
Zeolite & 37.0 & {$[5]$} \\
Carbon nanotube & 24.0 & {$[8]$} \\
Active carbon & 26.0 & {$[8]$} \\
\hline
\end{tabular}

Table 8. Surface nitrogen composition of AC-180 and creatinine adsorbed 180-AC derived from XPS.

\begin{tabular}{lcccccc}
\hline \multirow{2}{*}{ Sample } & \multicolumn{1}{l}{$\mathrm{N} \%$} & & & & \\
\cline { 2 - 7 } & $\mathrm{N}_{\text {total }}$ & $\mathrm{N} 1$ & $\mathrm{~N} 2$ & $\mathrm{~N} 3$ & $\mathrm{~N} 4$ & $\mathrm{~N} 5$ \\
\hline 180-AC & 0.74 & - & - & 0.33 & - & 0.41 \\
Creatinine adsorbed 180-AC & 2.58 & 0.91 & 0.70 & 0.57 & 0.15 & 0.41 \\
\hline
\end{tabular}

